\title{
Clinical Pharmacist's Intervention to Improve Medication Titration for Heart Failure: First Experience from Sudan
}

\author{
Kannan O Ahmed' \\ Imad Taj Eldin ${ }^{2}$ \\ Mirghani Yousif ${ }^{\prime}$ \\ Ahmed A Albarraq ${ }^{3}$ \\ Bashir A Yousef $\mathbb{D D}^{4}$ \\ Nasrein Ahmed ${ }^{5}$ \\ Anas Babiker ${ }^{6}$
}

'Department of Clinical Pharmacy, Faculty of Pharmacy, University of Gezira, Wad Medani, Sudan; ${ }^{2}$ Department of Pharmacology, Faculty of Pharmacy, University of Gezira, Wad Medani, Sudan; ${ }^{3}$ Pharmacy Practice Research Unit, Department of Clinical Pharmacy, College of Pharmacy, Jazan University, Jazan, Saudi Arabia; ${ }^{4}$ Department of Pharmacology, Faculty of Pharmacy, University of Khartoum, Khartoum, Sudan; ${ }^{5}$ Department of Cardiology, Ahmed Gasim Cardiac Surgery and Renal Transplantation Centre, Khartoum, Sudan; ${ }^{6}$ Department of Cardiology, Royal Care International Hospital, Khartoum, Sudan
Correspondence: Kannan O Ahmed Department of Clinical Pharmacy, Faculty of Pharmacy, University of Gezira, Hospital Street No. I, Wad Medani, 21II2, Sudan

Tel +249 I2I86000I

Fax +24951I86II80

Email omerkannan@gmail.com
Background: Medications known to improve outcomes in heart failure (HF) are either not prescribed or prescribed at sub-therapeutic doses. The addition of clinical pharmacists to the HF team positively impacts optimizing prognostic medications for a patient with HF with reduced ejection fraction (HFrEF).

Objective: To assess the intervention of the clinical pharmacist as part of the multidisciplinary (MD) team in up-titration to achieve target doses of key therapeutic agents for HFrEF.

Methods: This was a prospective one group pretest-posttest interventional study; a comparison of the target dose achievement of key therapeutic agents for HFrEF was performed before and after clinical pharmacist interventions.

Results: Out of $110 \mathrm{HFrEF}$ patients, $57.3 \%$ were males, and the mean age of patients was 55.8 years (SD 12.6). Cardiomyopathy was the leading cause of HF. At baseline, $86 \%$ were on angiotensin-converting enzyme inhibitors/angiotensin receptor blockers/angiotensin receptor-neprilysin inhibitors (ACEIs/ARBs/ARNi) and $93.6 \%$ on beta blockers (BBs). At the end of study, the proportion of patients achieved the target dose was significantly increased ( 0 vs $77.4 \%, 6.8$ vs $85.4 \%$, and 0 vs 55.6\%) for ACEIs, ARBs and ARNi, respectively, and $(8.6 \%$ vs $66.1 \% ; \mathrm{P}=0.001)$ for $\mathrm{BBs}$. Moreover, the up-titration process was associated with significant improvement in most clinical as ejection fraction and New York Heart Association (NYHA) scale and laboratory characteristics.

Conclusion: As a part of the MD team in the outpatient HF clinic, the clinical pharmacists increased the percentage of HFrEF patients achieving the target or maximal doses of key therapeutic agents and improving clinical and laboratory parameters.

Keywords: clinical pharmacist, intervention, heart failure, medications titration, Sudan

\section{Introduction}

Heart failure (HF) is a serious, progressive, disabling, and prevalent clinical syndrome, with significant morbidity, mortality, and increasing cost. ${ }^{1,2}$ The burden of HF is increasing in sub-Saharan Africa (SSA) and is now considered a significant cause of cardiovascular diseases (CVDs) affecting young people and carrying a higher rate of in-hospital mortality than other regions in the globe. ${ }^{3}$ In Sudan, the exact statistics (prevalence, incidence, mortality, hospitalization rate, management, and total cost) of HF are unknown. However, limited numbers of hospitalbased studies had been published. ${ }^{4-7}$

For patients with HFrEF, defined by the ejection fraction $(\mathrm{EF}) \leq 40 \%$, morbidity, and mortality are reduced with target doses of key therapeutic medications such 
as: 1) Angiotensin-converting enzyme inhibitors (ACEIs), 2) Angiotensin receptor blockers (ARBs), 3) Angiotensin receptor-Neprilysin inhibitors (ARNi), 4) beta blockers (BBs), and 5) Mineralocorticoid receptor antagonist (MRA). According to guidelines, these medications should be initiated and up-titrated every two weeks to the target or maximal tolerated doses to achieve optimal outcomes. ${ }^{8,9}$ However, the target dose achievement is an exhausting and challenging process for the physicians due to many overlapping reasons, such as HF needs several drugs to be used at the same time, while handling side effects. ${ }^{10}$ Despite dissemination of guidelines, in the realworld practice, management of HFrEF remained suboptimal. $^{11,12}$

Disease management programs (DMPs) such as HF clinic were found to be an effective tactic compared to the usual care in optimizing patients with HF and now is recommended by international guidelines to be practiced in a MD team. ${ }^{13}$ Clinical pharmacists are important members of this MD team and can significantly optimize drug regimens and promote medication adherence. ${ }^{14}$ Clinical pharmacy provision in Sudan is in a dynamic state showing positive promising changes in the past years. ${ }^{15}$ Currently, large numbers of hospitals in Khartoum state have started distinguishing clinical pharmacists' value and have recruited them to establish their units and services. Clinical pharmacy in Sudan is considered at an early stage. To the best of our knowledge, there was no published data about clinical pharmacists' role as one of the MD teams who optimize treatment for HFrEF patients in Sudan. Thus, we carried out this study; firstly, to assess the role of clinical pharmacists in increasing the percentage of patients on ACEIs, ARBs, ARNi, and BBs to the target doses, secondly, to describe the changes of clinical and laboratory parameters among Sudanese patients visiting outpatients' HF clinic.

\section{Methodology}

\section{Participants and Setting}

A prospective one group pretest-posttest interventional study was conducted at the outpatient HF clinic at Ahmed Gasim Cardiac Surgery and Renal Transplantation Center from August 2018 to June 2019. Ahmed Gasim is a tertiary hospital in Khartoum, Sudan, with 230 beds distributed between cardiology and nephrology units. It was the first cardiac center in Sudan, established in 1997. HF clinic in the hospital was established in
June 2018 as the first MD clinic in Sudan. The MD team consists of a consultant cardiologist, clinical pharmacy specialist, medical officer, nurse, dietician, psychologist, and cardiac rehabilitation specialist. Patients were eligible for the study if; their aged 18 years and above, documented $\mathrm{EF} \leq 40 \%$, and were willing to participate. Patients were excluded from the study if they had documented EF $>40 \%$, cancer patients, and patients with cognitive impairment or psychiatric illnesses.

Patients were referred to the HF clinic by different consultant cardiologists. All eligible patients referred to the clinic were selected and asked to participate in the study after obtaining written informed consent. First patient was recruited on $1 / 8 / 2018$, and after four months, the last eligible patient was included in the study. Each selected patient was asked to complete six months followup period in the clinic as described in the workflow (Figure 1). After that, patients were discharged from the HF clinic to their original unit. One hundred twenty-five patients were involved; fifteen of them failed to complete the study period because of commitment.

Data were collected using a questionnaire composed of demographic data, disease and treatment characteristics. The questionnaire was filled once for every patient at the beginning of the study. Also, we used dosage adjustment, and follow-up form contained EF, weight, New York Heart Association (NYHA) class for HF symptoms classification, heart rate (HR), systolic blood pressure (SBP), diastolic blood pressure (DBP), serum potassium (K), serum sodium $(\mathrm{Na})$, urea, serum creatinine (Scr), drug and doses status. This form was filled by a clinical pharmacist every patient's visit during the study period.

\section{Clinical Pharmacist Intervention}

A registered clinical pharmacy specialist with two years' experience in cardiology and consultant cardiologist joined three presentations conducted by the research investigator to clarify their roles and responsibilities in the MD clinic settings. The initiation, up-titration, changing between drugs' classes using equivalent doses, and stopping of ACEIs, ARBs, ARNi, and BBs were the responsibilities of the clinical pharmacist. Information about HF medication regimens (name, doses, and frequency) was carefully used to assess key therapeutic medications' up-titration. In addition to information about other medications such as herbal, over the counter (OTC), and medications to treat comorbidities were also assessed in terms of optimal doses and drug interactions. Target doses were defined as 


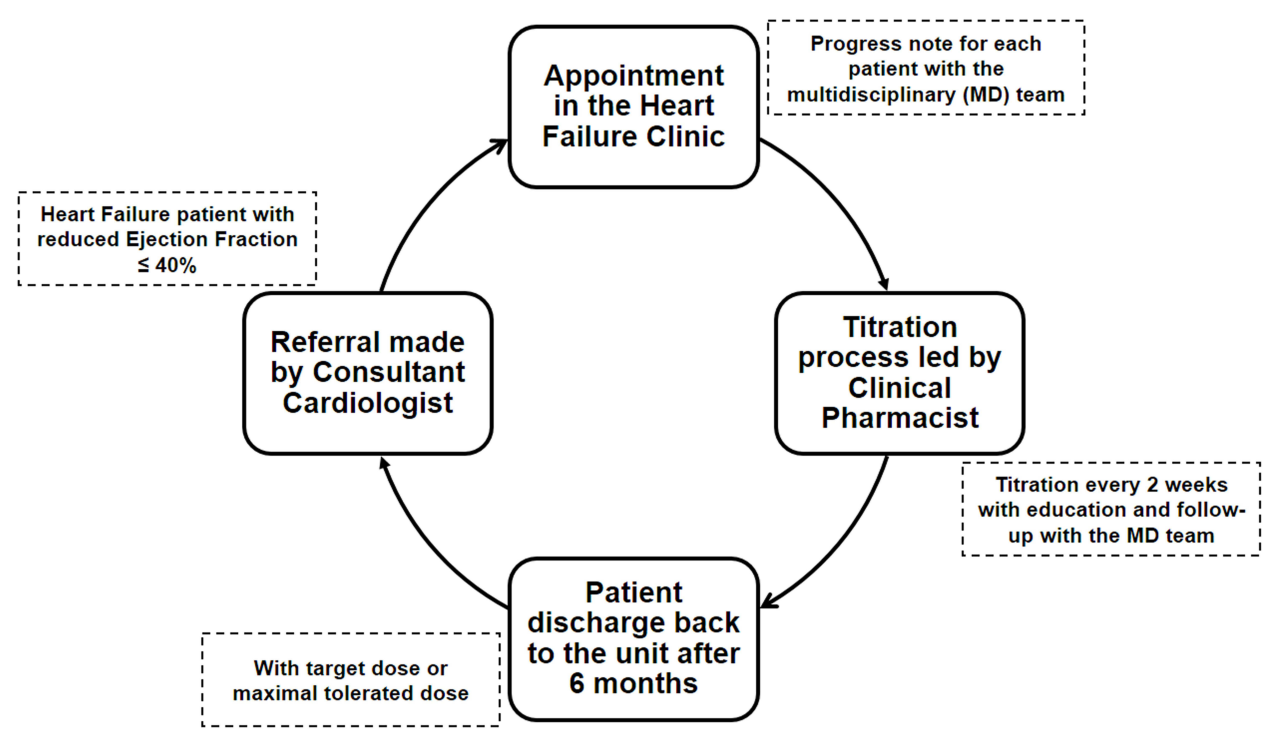

Figure I Workflow showing heart failure patient journey to and from heart failure clinic.

guideline-recommended doses. ${ }^{9}$ Maximum tolerated doses were defined as the highest doses a patient could tolerate without physiological limitations such as fatigue (mainly due to dose increases), bradycardia ( $\mathrm{HR} \leq 55 \mathrm{Bpm})$, hypotension ( $\mathrm{SBP} \leq 95 \mathrm{~mm} \mathrm{Hg}, \mathrm{DBP} \geq 55 \mathrm{~mm} \mathrm{Hg}$ ), hyperkalemia $(\mathrm{K} \geq 5.9 \mathrm{mEq} / \mathrm{L})$, or worsening renal function (Srcr $\geq 30 \%$ baseline). ${ }^{16}$ In the normal situation, the titration process was performed every 2 weeks. However, patients who developed side effects or abnormal findings were asked to visit the HF clinic before 2 weeks.

Clinical assessment of patients was performed and documented by a cardiologist. Based on this clinical status, the clinical pharmacist took a suitable intervention to optimize ACEIs, ARBs, $\mathrm{ARNi}$, and $\mathrm{BBs}$ to the target or maximal tolerated dose according to the predefined protocol agreed by the consultant cardiologist. The protocol was designed based on the expert consensus decision pathway to optimize $\mathrm{HF}$ treatment published by the European Society of Cardiology (ESC) guideline. ${ }^{9}$

If the patient was a candidate for the up-titration, he/ she had given a scheduled appointment as per the protocol to manage the titration process. In each visit, the clinical pharmacist took about 15-25 minutes for patient's assessment which include interpretation of laboratory data, symptoms, interaction, and side effects of each drug in the plan. The number of visits depending on the clinical status of the HF patients, drug used, and initial drug doses, for example those who were on lisinopril were asked to come to the clinic more than patients on ramipril or candesartan. When decision was made for titration, the clinical pharmacist up titrate the dose to the next step according to the ESC guidelines, then discussed the changes made in drug therapy with the patients and explained the purpose of each drug and the importance of adherence to the prescribed regimen. Clinical pharmacist used verbal and written materials to educate patients about all medications on each clinic visit after a rehearsal for last visit messages to ensure better understanding. During the follow-up period, patients received many educational sessions about their medications. If patients' symptoms worsen, the clinical pharmacist was directly contacted the cardiologist for further case discussion and evaluation.

\section{Study Outcomes}

There were 2 primary endpoints: the percentage of patients who achieved target doses ACEIs/ARBs or ARNi and the percentage of patients who achieved target BBs doses. Secondary endpoints were changed in clinical and laboratory parameters as NYHA class, EF, Blood Pressure (BP), weight, electrolytes and renal function.

\section{Statistical Analysis}

Data were processed using Statistical Package for Social Sciences (SPSS), version 25 (IBM Corp., Armonk, New York, USA). Descriptive statistics were used to describe all variables. Frequencies and percentages were calculated for categorical variables. McNemar test and paired t-tests were conducted to examine the associations 
between explanatory variables and clinical pharmacist intervention to optimize HF medication.

\section{Ethics Statement}

This study adhered to the ethical guidelines of the 1975 Declaration of Helsinki and was approved by the Medical Ethical Committee-Ministry of Health-Khartoum State (Serial Number: KMOH-REC-2020-NO.3). All eligible patients referred to the clinic were selected and asked to participate in the study after obtaining written informed consent. All collected checklists were coded to ensure confidentiality throughout the study.

\section{Results}

\section{Demographics, Disease Characteristics} and Prescription Pattern for HF Patients

A total of 110 HFrEF patients completed the study's period (6 months). In this study, males predominated $57.3 \%$. The mean age of patients was 55.8 years (SD 12.6). Around $30 \%$ of participants were university graduates and $70 \%$ of patients were unemployed, as shown in (Table 1).

Regarding disease characteristics, as indicated in Table 1, the present study showed that the mean duration of HF was 1.65 years (SD 1.5), and the major causes of HF were cardiomyopathy (45.5\%), followed by CAD (40\%), HTN (9.1\%), while valvular heart diseases were only (3.6\%). About $20.9 \%$ of patients had three comorbid diseases; IHD, DM, and HTN, while the diseases that were commonly found in HF patients were reported at lower percentages, $8.2 \%$ and $3.6 \%$ for $\mathrm{AF}$ and chronic kidney diseases (CKD), respectively (Table 1).

Concerning the prescription pattern of HF medications, at the study's baseline, $40 \%$ and $37.3 \%$ were either on ARBs or ACEIs, respectively. Whereas $93.6 \%$ of patients were on BBs, and around $58.2 \%$ were using spironolactone. Furthermore, $8.2 \%$ of patients were using ARNi (sacubitril/valsartan), and only one patient was using Ivabradine. Additionally, $75.5 \%$ of the participants were on furosemide for symptomatic relief of HF (Table 2).

\section{Clinical Pharmacist Intervention and Up-Titration of HFrEF Medication}

The study highlighted the current situation in the treatment of Sudanese patients with HFrEF. Among those using ACEIs and ARNi, there was no patient on target doses of the key therapeutic agent at baseline, and only $6.8 \%$ of
Table I Demographic and Disease Characteristics of HF Patients $(n=110)$

\begin{tabular}{|c|c|}
\hline Demographics & Frequency (\%) \\
\hline \multicolumn{2}{|l|}{ Gender } \\
\hline Male & $63(57.3 \%)$ \\
\hline Female & 47 (42.7\%) \\
\hline Age, Mean \pm SD (years) & $55.8 \pm 12.6$ years \\
\hline \multicolumn{2}{|l|}{ Education Level } \\
\hline Illiterate & $22(20 \%)$ \\
\hline Primary school & $19(17.3 \%)$ \\
\hline Secondary school & $10(9.1 \%)$ \\
\hline Higher school & $26(23.6 \%)$ \\
\hline University & $33(30 \%)$ \\
\hline \multicolumn{2}{|l|}{ Employment } \\
\hline Employed & $33(30 \%)$ \\
\hline Unemployed & 77 (70\%) \\
\hline \multicolumn{2}{|l|}{ Etiology of HF } \\
\hline Cardiomyopathy & $50(45.5 \%)$ \\
\hline Coronary Artery Disease & $44(40 \%)$ \\
\hline HTN & $10(9.1 \%)$ \\
\hline Valvular Heart Disease & $4(3.6 \%)$ \\
\hline Others & $2(1.8 \%)$ \\
\hline HF Duration, Mean \pm SD (years) & $1.65 \pm 1.5$ \\
\hline \multicolumn{2}{|l|}{ Comorbidities } \\
\hline DM & II (I0\%) \\
\hline HTN & $13(11.8 \%)$ \\
\hline Dyslipidemia & $4(3.6 \%)$ \\
\hline IHD & 15 (13.6\%) \\
\hline Atrial Fibrillation & $9(8.2 \%)$ \\
\hline Chronic Kidney Disease & $4(3.6 \%)$ \\
\hline $\mathrm{DM}+\mathrm{HTN}$ & 7 (6.4\%) \\
\hline $\mathrm{DM}+\mathrm{HTN}+\mathrm{IHD}$ & $23(20.9 \%)$ \\
\hline Others & II (I0\%) \\
\hline No comorbidities & $13(1 \mathrm{I} .8 \%)$ \\
\hline
\end{tabular}

Abbreviations: SD, standard deviation; HTN, hypertension; DM, diabetes mellitus; IHD, ischemic heart diseases.

those using ARBs and 7 (11\%) vs 42 (49\%) of spironolactone users were on target doses before clinical pharmacist intervention. At the end of 6 months, the proportion of patients achieving the target dose was significantly increased ( 0 vs $77.4 \%, 6.8$ vs $85.4 \%$, and 0 vs $55.6 \%$ ) for ACEIs, ARBs and ARNi, respectively (Table 3). Similarly, the mean doses of ACEIs, ARBs, and ARNi were significantly increased at the end of the study (Table 3). Although a high percent of BBs were utilized in this study, only $8.6 \%$ of patients were on target doses (Table 3). The clinical pharmacist intervention has significantly increased the percentage of patients achieving the 
Table 2 Prescription Pattern of HF Medications at Baseline $(n=110)$

\begin{tabular}{|l|c|}
\hline Drugs & Frequency (\%) \\
\hline ACEls & $4 I(37.3 \%)$ \\
ARBs & $44(40 \%)$ \\
ARNi & $9(8.2 \%)$ \\
BBs & $103(93.6 \%)$ \\
Spironolactone & $64(58.2 \%)$ \\
Ivabradine & $1(0.9 \%)$ \\
Furosemide & $83(75.5 \%)$ \\
Non-HF drugs & $86(78.2 \%)$ \\
\hline
\end{tabular}

Abbreviations: ACEls, angiotensin converting enzyme inhibitors; ARBs, angiotensin receptor blockers; ARNi, angiotensin receptor-neprilysin inhibitors; BBs, beta blockers; HF, heart failure.

target or maximal tolerated doses of BBs (8.6\% vs $66.1 \%$; $P=0.001)$. Furthermore, the mean dose of Bisoprolol was also significantly increased at the final visit of patients. In the same mode, the clinical pharmacist significantly increased the target doses of spironolactone (11\% vs $49 \% ; \mathrm{P}=0.001$ ) as presented in (Table 3 ).

At the end of the follow-up, among Sudanese patients with HFrEF, the up-titration was significantly associated with improvement of most clinical such as: EF, weight, NYHA class. On the other hand, nonsignificant changes were occurring in laboratory parameters as shown in Table 4. On the other hand, the clinical data and laboratory characteristics baseline and after 6 months for patients on maximal tolerated HF medications doses were presented (Tables 5 and 6). Throughout the study, we failed to increase doses of HF medications to the target or maximal tolerated level due to different reasons. For instance, rapid increases in $\mathrm{K}$ and Sr.cr were the most common barriers to up-titrating the ACEIs (6 patients), ARBs (1 patient), and four patients using ARNi

Table 3 Target Doses Achievement Before and After Clinical Pharmacist Intervention

\begin{tabular}{|c|c|c|c|c|}
\hline Drugs Group & & $\begin{array}{l}\text { Number of Patients } \\
\text { Using Drugs }\end{array}$ & $\begin{array}{c}\text { Number of Patients Achieved } \\
\text { Target Doses (\%) }\end{array}$ & $P$ value \\
\hline ACEls & $\begin{array}{l}\text { Before intervention } \\
\text { After Intervention }\end{array}$ & $\begin{array}{l}41 \\
53\end{array}$ & $\begin{array}{c}0(0 \%) \\
41 \text { (77.4\%) }\end{array}$ & 0.001 \\
\hline ARBs & $\begin{array}{l}\text { Before intervention } \\
\text { After Intervention }\end{array}$ & $\begin{array}{l}44 \\
48\end{array}$ & $\begin{array}{c}3(6.8 \%) \\
4 I(85.4 \%)\end{array}$ & 0.001 \\
\hline $\mathrm{ARNi}$ & $\begin{array}{l}\text { Before intervention } \\
\text { After Intervention }\end{array}$ & $\begin{array}{l}9 \\
9\end{array}$ & $\begin{array}{c}0(0 \%) \\
5(55.6 \%)\end{array}$ & 0.031 \\
\hline BBs & $\begin{array}{l}\text { Before intervention } \\
\text { After Intervention }\end{array}$ & $\begin{array}{l}103 \\
109\end{array}$ & $\begin{array}{c}9(8.6 \%) \\
72(66.1 \%)\end{array}$ & 0.001 \\
\hline \multirow[t]{3}{*}{ Spironolactone } & $\begin{array}{l}\text { Before intervention } \\
\text { After Intervention }\end{array}$ & $\begin{array}{l}64 \\
85\end{array}$ & $\begin{array}{c}7(11 \%) \\
42(49 \%)\end{array}$ & 0.001 \\
\hline & \multicolumn{2}{|c|}{ Initial Dose } & Final Dose & \multirow[t]{2}{*}{$P$ value } \\
\hline & \multicolumn{2}{|c|}{ Mean \pm SD $(\mathrm{mg})$} & Mean \pm SD $(\mathrm{mg})$ & \\
\hline $\begin{array}{l}\text { ACEIs } \\
\text { Lisinopril } \\
\text { Ramipril }\end{array}$ & & $\begin{array}{l} \pm 4.85 \\
\pm 1.22\end{array}$ & $\begin{array}{c}31.77 \pm 10.15 \\
9.31 \pm 1.75\end{array}$ & $\begin{array}{l}0.001 \\
0.001\end{array}$ \\
\hline $\begin{array}{l}\text { ARBs } \\
\text { Valsartan } \\
\text { Candesartan }\end{array}$ & $\begin{array}{r}8 \\
11.6\end{array}$ & $\begin{array}{l} \pm 0.0 \\
\pm 8.35\end{array}$ & $\begin{aligned} 146.67 & \pm 31.14 \\
29.56 & \pm 6.29\end{aligned}$ & $\begin{array}{l}0.001 \\
0.001\end{array}$ \\
\hline $\begin{array}{l}\text { ARNi } \\
\text { Sacubitril/Valsartan }\end{array}$ & \multicolumn{2}{|c|}{$66.67 \pm 25$} & $155.56 \pm 52.7$ & 0.001 \\
\hline $\begin{array}{l}\text { BBs } \\
\text { Bisoprolol } \\
\text { Carvedilol }\end{array}$ & $\begin{array}{l}4.1 \\
10 .\end{array}$ & $\begin{array}{l} \pm 2.19 \\
\pm 3.61\end{array}$ & $\begin{array}{c}8.18 \pm 2.59 \\
35.42 \pm 25.26\end{array}$ & $\begin{array}{l}0.001 \\
0.184\end{array}$ \\
\hline Spironolactone & \multicolumn{2}{|c|}{$27.5 \pm 7.6$} & $37.5 \pm 12.6$ & 0.001 \\
\hline
\end{tabular}

Abbreviations: SD, standard deviation; ACEls, angiotensin converting enzyme inhibitors; ARBs, angiotensin receptor blockers; ARNi, angiotensin receptor-neprilysin inhibitors; BBs, beta blockers. 
Table 4 Comparison of Clinical, Laboratory Characteristics Before and After Pharmacist Intervention

\begin{tabular}{|c|c|c|c|}
\hline \multirow[t]{2}{*}{ Characteristics } & Before Intervention & After Intervention & \multirow[t]{2}{*}{$P$ value } \\
\hline & Mean \pm SD & Mean \pm SD & \\
\hline EF & $30.9 \pm 7.2$ & $35.5 \pm 10.4$ & 0.001 \\
\hline HR (bpm) & $73.7 \pm 10.2$ & $64.3 \pm 6.6$ & 0.001 \\
\hline $\mathrm{SBP}(\mathrm{mm} \mathrm{Hg})$ & $120.4 \pm 20$ & $110.4 \pm 15.3$ & 0.001 \\
\hline $\mathrm{DBP}(\mathrm{mm} \mathrm{Hg})$ & $76.2 \pm 9.9$ & $69.9 \pm 7.1$ & 0.001 \\
\hline $\mathrm{K}(\mathrm{mmol} / \mathrm{l})$ & $3.9 \pm 0.5$ & $4.2 \pm 0.5$ & 0.001 \\
\hline Urea $(\mathrm{mmol} / \mathrm{l})$ & $35.7 \pm 22.2$ & $33.0 \pm 13.9$ & 0.133 \\
\hline $\operatorname{Scr}(m g / d l)$ & $1.055 \pm 0.4$ & $0.9 \pm 0.3$ & 0.013 \\
\hline Weight (kg) & $71.7 \pm 13.7$ & $70.8 \pm 13$ & 0.002 \\
\hline $\mathrm{Na}(\mathrm{mmol} / \mathrm{l})$ & $135.6 \pm 3.5$ & $135.4 \pm 2.9$ & 0.65 \\
\hline NYHA Class & $\begin{array}{c}\text { Before Intervention } \\
\text { Number of Patients (\%) }\end{array}$ & $\begin{array}{c}\text { After Intervention } \\
\text { Number of Patients (\%) }\end{array}$ & $P$ value \\
\hline I & $0(0 \%)$ & 71 (64.5\%) & 0.001 \\
\hline II & $65(59.1 \%)$ & $33(30 \%)$ & \\
\hline III & 42 (38.2\%) & $6(5.5 \%)$ & \\
\hline IV & $3(2.7 \%)$ & $0(0 \%)$ & \\
\hline
\end{tabular}

Abbreviations: SD, standard deviation; EF, ejection fraction; HR, heart rate; SBP, systolic blood pressure; DBP, diastolic blood pressure; K, serum potassium; Scr, serum creatinine; Na, serum sodium; NYHA, New York Heart Association.

Table 5 Comparison of Clinical, Laboratory Characteristics Before and After Pharmacist Intervention for Patients on Maximum Tolerated Doses of ACEls*/ARBs**/ARNi*** $(n=22)$

\begin{tabular}{|c|c|c|c|}
\hline \multirow[t]{2}{*}{ Characteristics } & Before Intervention & After Intervention & \multirow[t]{2}{*}{$P$ value } \\
\hline & Mean \pm SD & Mean \pm SD & \\
\hline EF & $28.5 \pm 8.5$ & $29.3 \pm 9.5$ & 0.237 \\
\hline HR (bpm) & $75.1 \pm 13$ & $63.05 \pm 8.4$ & 0.001 \\
\hline $\mathrm{SBP}(\mathrm{mm} \mathrm{Hg})$ & $116.1 \pm 20.1$ & $103.4 \pm 11.6$ & 0.001 \\
\hline $\mathrm{DBP}(\mathrm{mm} \mathrm{Hg})$ & $72.9 \pm 10.2$ & $67.9 \pm 7.03$ & 0.006 \\
\hline $\mathrm{K}(\mathrm{mmol} / \mathrm{l})$ & $3.9 \pm 0.6$ & $4.2 \pm 0.5$ & 0.029 \\
\hline Urea $(\mathrm{mmol} / \mathrm{l})$ & $37.6 \pm 14.5$ & $33.6 \pm 11.5$ & 0.104 \\
\hline Scr $(m g / d l)$ & $1.13 \pm 0.38$ & $1.04 \pm 0.25$ & 0.013 \\
\hline Weight (kg) & $71.4 \pm 12.4$ & $71.2 \pm 11.2$ & 0.747 \\
\hline $\mathrm{Na}(\mathrm{mmol} / \mathrm{l})$ & $136.2 \pm 3.6$ & $134.8 \pm 3.5$ & 0.088 \\
\hline NYHA Class & $\begin{array}{c}\text { Before Intervention } \\
\text { Number of Patients (\%) }\end{array}$ & $\begin{array}{c}\text { After Intervention } \\
\text { Number of Patients (\%) }\end{array}$ & $P$ value \\
\hline I & $0(0 \%)$ & $9(45.5 \%)$ & 0.002 \\
\hline ॥ & $13(59.1 \%)$ & $10(40.9 \%)$ & \\
\hline III & $9(40.9 \%)$ & $3(13.6 \%)$ & \\
\hline IV & $0(0 \%)$ & $0(0 \%)$ & \\
\hline
\end{tabular}

Notes: *Angiotensin converting enzyme inhibitors (ACEls) distributed as Lisinopril $20 \mathrm{mg}=7$ patients, Ramipril $10 \mathrm{mg}=5$ patients, $* *$ Angiotensin receptor blockers (ARBs) distributed as Valsartan $80 \mathrm{mg}=2$, Candesartan $8 \mathrm{mg}=1$. Candesartan $16 \mathrm{mg}=3$ patients. $* * *$ Angiotensin receptor-neprilysin inhibitors $(A R N i)$ Sacubitril/Valsartan $100=4$ patients.

Abbreviations: SD, standard deviation; EF, ejection fraction; HR, heart rate; SBP, systolic blood pressure. DBP; diastolic blood pressure; K, serum potassium; Scr, serum creatinine; Na, serum sodium; NYHA, New York Heart Association.

reported hypotensive effect with doses increment, and they refused the up-titration. Likewise, because of bradycardia (HR less $55 \mathrm{Bpm}$ ) and fatigue (patients experienced mainly with dose increment), we failed to titrate the doses to ten patients using bisoprolol $2.5 \mathrm{mg}$ once daily and one patient on carvedilol $6.25 \mathrm{mg}$ twice daily. 
Table 6 Comparison of Clinical, Laboratory Characteristics Before and After Pharmacist Intervention for Patients on Maximum Tolerated Doses of BBs* $(n=27)$

\begin{tabular}{|c|c|c|c|}
\hline \multirow[t]{2}{*}{ Characteristics } & Before Intervention & After Intervention & \multirow[t]{2}{*}{$P$ value } \\
\hline & Mean \pm SD & Mean \pm SD & \\
\hline EF & $30 \pm 8.6$ & $30.8 \pm 9.7$ & 0.288 \\
\hline HR (bpm) & $74.6 \pm 10.3$ & $61.7 \pm 7.2$ & 0.001 \\
\hline SBP (mm Hg) & $118.7 \pm 18.7$ & $110.7 \pm 19.5$ & 0.002 \\
\hline $\mathrm{DBP}(\mathrm{mm} \mathrm{Hg})$ & $73.9 \pm 9.5$ & $67.8 \pm 6.1$ & 0.000 \\
\hline $\mathrm{K}(\mathrm{mmol} / \mathrm{l})$ & $4 \pm 0.6$ & $4.3 \pm 0.5$ & 0.017 \\
\hline Urea $(\mathrm{mmol} / \mathrm{l})$ & $35.8 \pm 25.1$ & $33.3 \pm 17.8$ & 0.556 \\
\hline Scr $(m g / d l)$ & $1.06 \pm 0.5$ & $\mathrm{I} . \mathrm{I} \pm 0.47$ & 0.113 \\
\hline Weight (kg) & $7 I \pm 10.9$ & $71.1 \pm 10.2$ & 0.761 \\
\hline $\mathrm{Na}(\mathrm{mmol} / \mathrm{l})$ & $135.4 \pm 3.9$ & $134.3 \pm 3$ & 0.188 \\
\hline NYHA Class & $\begin{array}{c}\text { Before Intervention } \\
\text { Number of Patients (\%) }\end{array}$ & $\begin{array}{c}\text { After Intervention } \\
\text { Number of Patients (\%) }\end{array}$ & $P$ value \\
\hline I & $0(0 \%)$ & II (40.7\%) & 0.001 \\
\hline II & $16(59.3 \%)$ & $12(44.4 \%)$ & \\
\hline III & II (40.7\%) & $4(14.8 \%)$ & \\
\hline IV & $0(0 \%)$ & $0(0 \%)$ & \\
\hline
\end{tabular}

Note: *Beta blockers (BBs), all Patients were on Bisoprolol $5 \mathrm{mg}$.

Abbreviations: SD, standard deviation; EF, ejection fraction; HR, heart rate; SBP, systolic blood pressure; DBP, diastolic blood pressure; K, serum potassium; Scr, serum creatinine; Na, serum sodium; NYHA, New York Heart Association.

\section{Discussion}

We report the first experience in an MD HF clinic in Sudan and the first utilization of clinical pharmacy services in HF patients. The establishment of this clinic helps to serve patients with $\mathrm{HFrEF}$ in specialized mode, promotes the concept of MD team, optimizes patients, medications, share features and characteristics of Sudanese patients with HF, and act as a nucleus for a more advanced HF program in Sudan. Our findings highlight the role of clinical pharmacist intervention in achieving the target dose for key therapeutic agents and improving the clinical outcomes for HFrEF patients.

Our results showed that $110 \mathrm{HFrEF}$ patients were included in this study, the mean age of them was 55.8 \pm 12.6 years, which coincided with what was reported in Sudan. ${ }^{7}$ Both findings were similar to data from SSA, which revealed that $\mathrm{HF}$ is a disease of young and middle age. ${ }^{17}$ Nonetheless, the mean age is about 8 years younger than patients in studies reported from developed countries. ${ }^{18}$ This might be due to the younger population structure in Sudan. ${ }^{19}$ Etiologically, the major causes of HF were cardiomyopathy and CAD, which are in line with a report about the most prevalent causes of HF in Sudan. ${ }^{20}$ Moreover, CAD was found to be the second HF etiology, which might be due to referral bias, as patients with CAD would traditionally refer to Ahmed Gasim hospital known for caring for patients with ischemic heart disease rather than the general hospital where a hypertensive heart disease might be expected to be more prevalent.

The study indicated a satisfactory class adherence to ACEIs/ARBs/ARNi, BBs, and MRAs for HFrEF and consistent with previous studies in Sudan and SSA and in Gulf DYSPNEA registry. ${ }^{7,21-23}$ Among studied patients, $86 \%$, 93.6\%, and 58.2\% were prescribed ACEIs/ARBs/ARNi, BBs, and MRAs therapy, respectively (Table 2). Unfortunately, the international registries and our study described good adherence to evidence-based medications also reported use of suboptimal doses, as most patients were not prescribed guideline-recommended target doses of these medications. ${ }^{23,24}$

Clinical pharmacists in HF management have many roles in different settings and through diverse approaches. They can work in inpatients or outpatient's settings, as independent health-care providers or as a part of MD team. This is the first study evaluating the role of clinical pharmacist in outpatient settings in Sudan, in which clinical pharmacist interact face to face with HF patients in the HF clinic.

The addition of clinical pharmacists to the HF team was earlier reported in the Pharmacist in Heart Failure 
Assessment Recommendation and Monitoring (PHARM) study. ${ }^{25}$ In which a pharmacist performed medication evaluations, provided patient education, and made medication recommendations to a physician. Findings showed that clinically this led to a decrease in all-cause mortality and HF events and an increase in ACEIs doses. Similarly, collaborative work between pharmacists and physicians in optimization of HF therapy was reported in Heart Failure and Optimal Outcomes from Pharmacy Study (HOOPS). The pharmacist recommendation led to an increase in the prescription of ACEIs or ARBs, and those who achieved the target doses of ACEIs or ARBs were statistically increased. On the other hand, although the number of patients using BBs increased, those who achieved the target doses did not show statistical significance. $^{26}$

PHARM, HOOPS and our study share some similarities and differences. In all studies' patients were stable and include pharmacists-physician collaboration approach. Moreover, in HOOPS pharmacist initiated, discontinued, and modified medications to optimize HF medication therapy with physician agreement. However, in our study, the pharmacist followed a predefined protocol, and there was no need for another agreement or rejection of the physician. Additionally, nonspecialized pharmacists in the HOOPS followed the patient for only three or four visits, regardless of whether the patient achieved target doses or not. While, in our study, a clinical pharmacist with two years' experience in cardiology followed HF patients until they achieved target doses or maximum tolerated doses of medications. Furthermore, our results found that pharmacists significantly increased the percentage of patients at target doses of ACEIs/ARBs or ARNi and BBs.

Our findings were similar to another two retrospective studies, in which pharmacist-led HF medication titration increased the percentage of patients achieving optimal doses of ACEIs/ARBs and BBs. ${ }^{11,16}$ However, the current study has noteworthy differences, it is an interventional study and evaluated the clinical pharmacist's role as part of the MD team. Moreover, the study included the uptitration of ARNi, although it was utilized at a low percentage $(8.2 \%)$, this might be due to a very high cost of the drug as well as being out of governmental and private insurance coverage.

Our study faced many challenges. Firstly, lower rate of referral to the MD clinic. Secondly, bad perception of Sudanese patients towards high doses of medications; they thought that dose increments meant their HF condition was getting worse. Thirdly, shortage, unavailability of some medications, and high cost of HF drugs in Sudan. On the other hand, many limitations were also present; 1) it was nonrandomized, 2) a single-center study; and hence, it lacks the national representation of other patients treated in other cardiac hospitals in Sudan, 3) the study did not evaluate the mortality and different forms of hospitalization as 30 days or 6 months readmission which are directly correlated to HF mortality and increasing cost, 4) the reasons and barriers for lack of uptitration to the target doses at baseline were not assessed. Although we noticed that physiological limitations as symptomatic hypotension and fatigue did not significantly prevent the titration to the target doses, this might explain that Sudanese patients with HF in the present study were young and had fewer comorbidities. Thus, future studies with a more robust study design, multicenter, larger sample size, evaluating HF clinical outcomes are really needed. Despite all these challenges and limitations, our findings are interesting as they highlighted the successful expanded role of clinical pharmacists in managing HF patients in specialized mode. These encouraging results associated with this HF clinic could be duplicated in other cardiac centers in Sudan and African countries.

\section{Conclusion}

As a part of the MD team in the outpatient HF clinic, the clinical pharmacists increased the percentage of HFrEF patients achieving the target of key therapeutic agents and improving clinical and some laboratory parameters.

\section{Funding}

There is no funding to report.

\section{Disclosure}

The authors declare that they have no conflicts of interest for this work.

\section{References}

1. Atallah B, Sadik ZG, Osoble AA, et al. Establishing the first pharmacist-led heart failure medication optimization clinic in the Middle East Gulf Region. Pharmacotherapy. 2020;3(5):877-884.

2. Carroll R, Mudge A, Suna J, Denaro C, Atherton J. Prescribing and up-titration in recently hospitalized heart failure patients attending a disease management program. Int $J$ Cardiol. 2016;216:121-127. doi:10.1016/j.ijcard.2016.04.084 
3. Carlson S, Duber HC, Achan J, et al. Capacity for diagnosis and treatment of heart failure in sub-Saharan Africa. Heart. 2017;103 (23):1874-1879. doi:10.1136/heartjnl-2016-310913

4. Almobarak AO, Awadalla H, Osman M, Ahmed MH. Prevalence and predictive factors for heart failure among Sudanese individuals with diabetes: population based survey. J Public Health Emerg. 2018;2 (5):17-25. doi:10.21037/jphe.2018.04.03

5. Omer MA, Gar-elnabi ME, Alsayyari AA, Yousuf JH, Mohammed MF. Studying of heart diseases prevalence, distribution and cofactors in Sudanese population. Int J Res Med Sci. 2016;4 (1):206-2011. doi:10.18203/2320-6012.ijrms20160032

6. Suliman A. The state of heart disease in Sudan. Cardiovasc J Afr. 2011;22(4):191-196. doi:10.5830/CVJA-2010-054

7. Khalil SI, Khalil S, Albadri HK, et al. Emergence of ischemic cardiomyopathy as the main cause of heart failure in urban Sudanese population. Int Cardiovasc Forum J. 2015;2:37-41. doi:10.17987/icfj.v2i1.82

8. Yancy CW, Januzzi JL, Allen LA, et al. 2017 ACC expert consensus decision pathway for optimization of heart failure treatment: answers to 10 pivotal issues about heart failure with reduced ejection fraction: a report of the American College of Cardiology Task Force on Expert Consensus Decision Pathways. J Am Coll Cardiol. 2018;71 (2):201-230.

9. Ponikowski P, Voors AA, Anker SD, et al. 2016 ESC Guidelines for the diagnosis and treatment of acute and chronic heart failure: the Task Force for the diagnosis and treatment of acute and chronic heart failure of the European Society of Cardiology (ESC). Developed with the special contribution of the Heart Failure Association (HFA) of the ESC. Eur J Heart Fail. 2016;18(8):891-975.

10. Marti CN, Fonarow GC, Anker SD, et al. Medication dosing for heart failure with reduced ejection fraction-opportunities and challenges. Eur J Heart Fail. 2019;21(3):286-296. doi:10.1002/ejhf.1351

11. Bhat S, Kansal M, Kondos GT, Groo V. Outcomes of a pharmacist-managed heart failure medication titration assistance clinic. Ann Pharmacother. 2018;52(8):724-732. doi:10.1177/ 1060028018760568

12. Ouwerkerk W, Voors A, Anker S, et al. Determinants and clinical outcome of uptitration of ACE-inhibitors and beta-blockers in patients with heart failure: a prospective European study. Eur Heart J. 2017;38(24):1883-1890. doi:10.1093/eurheartj/ehx026

13. Al-Bawardy R, Cheng-Lai A, Prlesi L, et al. Heart failure postdischarge clinic: a pharmacist-led approach to reduce readmissions. Curr Probl Cardiol. 2019;44(10):5. doi:10.1016/j.cpcardiol.2018.12.004

14. Hickey A, Suna J, Marquart L, et al. Improving medication titration in heart failure by embedding a structured medication titration plan. Int J Cardiol. 2016;224:99-106. doi:10.1016/j.ijcard.2016.09.001
15. Elsadig H, Weiss M, Scott J, Laaksonen R. Exploring the challenges for clinical pharmacists in Sudan. Int J Clin Pharm. 2017;39 (5):1047-1054. doi:10.1007/s11096-017-0521-8

16. Martinez AS, Saef J, Paszczuk A, Bhatt-Chugani H. Implementation of a pharmacist-managed heart failure medication titration clinic. Am $J$ Health Syst. 2013;70(12):1070-1076. doi:10.2146/ajhp120267

17. Ogah OS, Adebiyi A, Sliwa K. Heart failure in Sub-Saharan Africa. In: Topics in Heart Failure Management. IntechOpen; 2019:61.

18. Zubaid M, Rashed W, Ridha M, et al. Implementation of guideline-recommended therapies for patients with heart failure and reduced ejection fraction: a regional Arab Middle East experience. Angiology. 2020;71(5):431-437. doi:10.1177/0003319720905742

19. Mohamed AAO, Elhassan EAM, Mohamed AO, et al. Knowledge, attitude and practice of the Sudanese people towards COVID-19: an online survey. BMC Public Health. 2021;21(1):274. doi:10.1186/ s12889-021-10319-5

20. Noma M, Khali SI, Atabani SM, Homeida M. Prevalence and clinical presentations of dilated cardiomyopathy in Sudanese patients with heart failure. Open Sci J. 2017;2(4). doi:10.23954/osj.v2i4.1174

21. Bolon J, McCutcheon K, Klug E, Smith D, Manga P. Beta-blocker target dosing and tolerability in a dedicated heart failure clinic in Johannesburg. Cardiovasc J Afr. 2019;30(2):103-107. doi:10.5830/ CVJA-2019-001

22. Dokainish H, Teo K, Zhu J, et al. Heart failure in Africa, Asia, the Middle East and South America: the INTER-CHF study. Int J Cardiol. 2016;204:133-141. doi:10.1016/j.ijcard.2015.11.183

23. Zubaid M, Rashed W, Ridha M, et al. Design and rationale of Gulf documentation of ambulatory sick patients with heart failure (Gulf DYSPNEA) registry. Heart Views. 2018;19(3):81-84. doi:10.4103/ HEARTVIEWS.HEARTVIEWS_9_18

24. Komajda M, Cowie MR, Tavazzi L, et al. Physicians' guideline adherence is associated with better prognosis in outpatients with heart failure with reduced ejection fraction: the QUALIFY international registry. Eur J Heart Fail. 2017;19(11):1414-1423. doi:10.1002/ejhf.887

25. Gattis WA, Hasselblad V, Whellan DJ, O'connor CM. Reduction in heart failure events by the addition of a clinical pharmacist to the heart failure management team: results of the pharmacist in heart failure assessment recommendation and monitoring (PHARM) study. Arch Intern Med. 1999;159(16):1939-1945. doi:10.1001/ archinte.159.16.1939

26. Lowrie R, Mair FS, Greenlaw N, et al. The Heart failure and Optimal Outcomes from Pharmacy Study (HOOPS): rationale, design, and baseline characteristics. Eur J Heart Fail. 2011;13(8):917-924. doi:10.1093/eurjhf/hfr083
Integrated Pharmacy Research and Practice

\section{Publish your work in this journal}

Integrated Pharmacy Research and Practice is an international, peerreviewed, open access, online journal, publishing original research, reports, reviews and commentaries on all areas of academic and professional pharmacy practice. This journal aims to represent the academic output of pharmacists and pharmacy practice with particular focus on integrated care. All papers are carefully peer reviewed to ensure the highest standards as well as ensuring that we are informing and stimulating pharmaceutical professionals. The manuscript management system is completely online and includes a very quick and fair peer-review system, which is all easy to use. Visit http://www.dovepress.com/testimonials.php to read real quotes from published authors. 